que os pacientes, ou por crise aguda ou por alterações graves de comportamento, necessitam de internação em hospital psiquiátrico. É fato consagrado, hoje, que qualquer profissional que lida com pacientes psicóticos é contra a internação em grandes asilos, por longo prazo e com privação de liberdade. Mas simplesmente "desaparecer" com os hospitais psiquiátricos representa um novo reducionismo. No livro, apenas Ana Pitta faz referência aos hospitais psiquiátricos incluindo-os numa figura representando uma rede de recursos psicossociais. No GO 5, de Estévez e Baron, há recomendações de um "programa de atenção a pessoas com transtorno psicótico contínuo e alterações graves do comportamento". Referem que a prevalência de pacientes com essas necessidades especiais é de 15 por 100.000 habitantes. Estes, por sua vez, demandam cinco leitos por 100.000 habitantes (10.000 leitos por 200 milhões de habitantes), excluídos os que cometeram delitos e necessitam de unidades forenses. Os autores recomendam para esses pacientes mais graves a internação em UPHG por dois meses e, se não houver melhora, por mais dois meses. Caso não melhorem, recomendam a transferência para "unidades hospitalares de permanência média" por dois anos ou mais. Concluem que a reforma psiquiátrica é imperativa, mas precisa repensar e "integrar a hospitalização como um instrumento técnico importante no tratamento de determinadas condições psiquiátricas que deve estar presente dentro do conjunto de medidas que compreende o processo terapêutico...", como manifestou recentemente Josimar França, presidente da Associação Brasileira de Psiquiatria (ABP).

Itiro Shirakawa

Escola Paulista de Medicina, Universidade Federal de São Paulo (UNIFESP), São Paulo (SP), Brasil

\section{Referência rápida às diretrizes para o tratamento de transtornos psiquiátricos: compêndio 2004}

American Psychiatry Association. Porto Alegre: Artmed; 2005. ISBN 85-363-0447-2
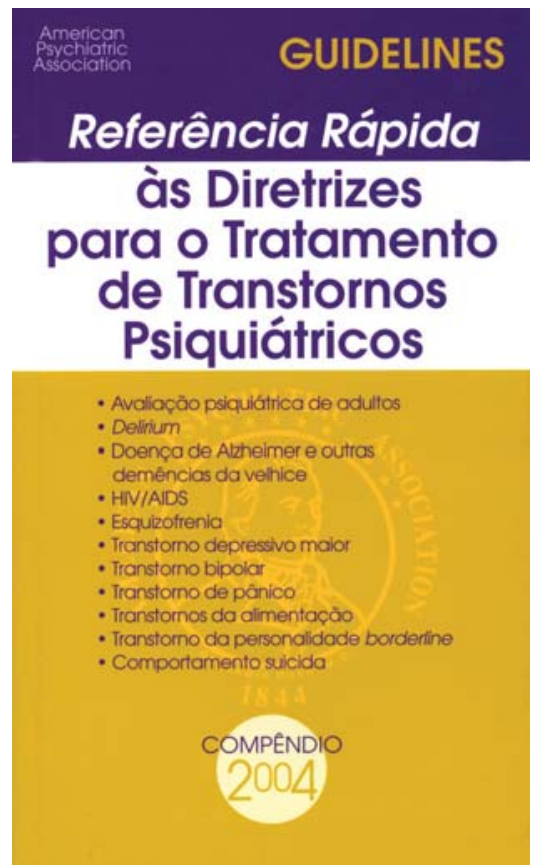

Este compêndio sumariza as diretrizes para o tratamento de transtornos psiquiátricos desenvolvidas pela American Psychiatry Association (APA) e originalmente publicadas no American Journal of Psychiatry, que contempla os tratamentos dos seguintes tópicos da clínica psiquiátrica: delirium, doença de Alzheimer e outras demências da velhice, HIV/AIDS, esquizofrenia, transtorno bipolar, transtorno do pânico, transtornos alimentares, transtorno de personalidade borderline e comportamento suicida. A terapêutica é abordada em seus vários aspectos de uma forma objetiva, através de frases curtas dentro de diagramas com setas que seguem uma seqüência lógica. Também são apresentadas tabelas claras e concisas.

O formato didático e resumido deste livro permite que os psiquiatras acessem, de forma rápida e fácil, orientações práticas baseadas em evidências na tomada de decisão de tratamento. Este tipo de publicação é importante porque, muitas vezes, a evidência científica terapêutica está diluída nos diferentes periódicos e não atende às reais necessidades dos clínicos, que precisam otimizar seu tempo com respostas rápidas e confiáveis para tratar seus pacientes. Este livro é definitivamente uma boa maneira de atualizar e melhorar a prática em terapêutica dos profissionais que estão na "linha de frente".

Contudo, como os próprios autores salientam, orientações rápidas não funcionam isoladamente. Para uma boa prática terapêutica e até mesmo para o bom uso do manual é necessária uma formação psiquiátrica consistente. O uso do julgamento clínico adequado associado às melhores evidências científicas disponíveis é o que constitui verdadeiramente a boa prática clínica. Os conhecimentos humanísticos, psicopatológicos e o retorno constante aos livros-texto, periódicos científicos e às próprias diretrizes de tratamento em texto completo são sempre necessárias, principalmente para psiquiatras em formação. É importante deixar claro que não abordar estes aspectos não é um defeito da publicação, pois em nenhum momento ela se propõe a avançar além da orientação rápida. Deve-se entender que, quando em diversas partes do livro está escrito que é necessário fazer uma "anamnese completa" ou "entender as angústias e expectativas do paciente" para tomar uma conduta terapêutica, está subentendido que isso é uma habilidade prévia e requisito básico para o psiquiatra.

Portanto, acredito que o livro apresenta um conteúdo científico excelente, está organizado de forma lógica e simples, e constitui-se em grande auxílio ao psiquiatra na prática clínica diária, mas não substitui a leitura de obras mais completas. De uma forma alegórica posso dizer que é uma ótima ferramenta para uma oficina já bem equipada. Seu formato permite fácil manuseio e facilita sua utilização no trabalho cotidiano com os pacientes.

\section{Fernando Kratz Gazalle}

Programa de Pós-Graduação em Ciências Médicas: Psiquiatria, Universidade Federal do Rio Grande do Sul (UFRGS), Porto Alegre (RS), Brasil

Laboratório de Psiquiatria Experimental, Hospital de Clínicas de Porto Alegre (HCPA), Porto Alegre (RS), Brasil 